\title{
Magnetic properties of the complex concentrated alloy system CoFeNi ${ }_{0.5} \mathrm{Cr}_{0.5} \mathrm{Al}_{\mathrm{x}}$
}

\author{
N. A. Morley, B. Lim, J. Xi, A. Quintana-Nedelcos \& Z. Leong \\ We study the change in magnetisation with paramagnetic $\mathrm{Al}$ addition in the $\mathrm{CoFeNi} \mathrm{Ni}_{0.5} \mathrm{Cr}_{0.5}-\mathrm{Al}_{\mathrm{x}}$ (x: 0 , \\ $0.5,1$, and 1.5) complex concentrated alloy. The compositions were developed utilising the Mulliken \\ electronegativity and d-electron/atom ratio. Spherical $\mathrm{FeCr}$ rich nanoprecipitates are observed for \\ $\mathrm{X}: 1.0$ and 1.5 in an AlCoNi-rich matrix. A 5 x increase in magnetisation (from 22 to $96 \mathrm{Am}^{2} / \mathrm{kg}$ ) \\ coincides with this nanoprecipitate formation-the main magnetic contribution is determined to \\ be from $\mathrm{FeCr}$ nanoprecipitates. The magnetisation increase is strange as paramagnetic Al addition \\ dilutes the ferromagnetic $\mathrm{Fe} / \mathrm{Co} / \mathrm{Ni}$ additions. In this paper we discuss the magnetic and structural \\ characterisation of the $\mathrm{CoFeNi} \mathrm{Ni}_{0.5} \mathrm{Cr}_{0.5}-\mathrm{Al}_{\mathrm{x}}$ composition and attempt to relate it to the interfacial \\ energy.
}

The innovation of new materials has been deemed to be the key topic for development of new technologies in our modern world. For alloys, the traditional approach has been to consider the effect of multiple dilute additions to a larger alloy matrix. New complex concentrated alloys (CCAs), which are near-equimolar multiple element alloys $(>3)$ challenge this view and have pushed alloy research towards the centre of phase diagrams ${ }^{1,2}$.

Multiple alloying components mean that they can possess large property permutations owing to the vast compositional space that they cover. Considerable work has been done on understanding how compositionalstructure affects mechanical properties. However, their functional properties are rarely the primary focus. As the base elements of CCAs are often CoFeNi (which is a known soft magnetic alloy), this can provide a basis for alloy design $^{1-5}$. Our motivation in this work is to therefore investigate the potential of CCAs as soft magnetic materials.

Studies of CoFeMnNi $+\mathrm{X},(\mathrm{X}=\mathrm{Al}, \mathrm{Cr}, \mathrm{Ga} \text {, or Sn })^{6}, \mathrm{CoFeCrNi}-\mathrm{X},(\mathrm{X}=\mathrm{Ga}, \mathrm{Sn}, \mathrm{Mn} \text {, or Al })^{7}$ show that Ga and $\mathrm{Al}$ additions tend to lead to the largest change in magnetisation in the system. Kormann et al. ${ }^{8}$ for CoFeNi$\mathrm{X}$ alloys $\left(\mathrm{X}=\mathrm{Cr}_{\mathrm{A}} \mathrm{Ag}_{\mathrm{B}}, \mathrm{Cr}_{\mathrm{A}} \mathrm{Au}_{\mathrm{B}}, \mathrm{Cr}_{\mathrm{A}} \mathrm{Pd}_{\mathrm{B}}\right.$, and $\left.\mathrm{Cr}_{\mathrm{A}} \mathrm{Cu}_{\mathrm{B}}\right)$ also reported the deleterious effect of $\mathrm{Cr}$ on saturation magnetisation ${ }^{9,10}$. Also, the literature showed process-dependant saturation magnetisation dependence of CoFe$\mathrm{CrNi}-\mathrm{Al}_{\mathrm{x}}$ on post-processing that may be related to this, but in general for $\mathrm{CoFeCrNi}-\mathrm{Al}_{\mathrm{x}}$, the phases change as $\mathrm{x}<0.3$ (FCC present), $0.5<\mathrm{x}<0.7$ (FCC + BCC present), and $\mathrm{x}>0.9$ (BCC present) ${ }^{6,11,12}$. FeCr-rich particles tend to form in a CoNiAl-rich matrix above $\mathrm{x}>0.9$, but the form of the particles depends upon the processing conditions $^{12}$.

The influence of processing is important: in the CoFeCrNi system the magnetisation and Curie Temperature depends upon alloy fabrication processes (mechanical alloying vs. as-cast) due to increased Cr ordering (increasing its antiferromagnetic contribution $)^{13}$. It has been shown that antiferromagnetic Cr clusters can display ferromagnetic behaviour when atomic-scale disorder is present ${ }^{14}$. The BCC and B2 structure is coherently present in $\mathrm{CoFeCrNi}-\mathrm{Al}_{\mathrm{x}}{ }^{15,16}$ and results in a change in strain and interfacial energy ${ }^{17,18}$. This may change the magnetisation of the composition as magnetic fields have been shown to affect interfacial energy in steel ${ }^{19}$, which have similar alloying elements to $\mathrm{CoFeCrNi}-\mathrm{Al}_{\mathrm{x}}$. Taken together, this suggests that to maximise saturation magnetisation in this composition, heat treatment to promote nucleation and growth of the disordered structure is required. This also homogenises the non-equilibrium phases from the arc-melting synthesis, providing a reference for future studies ${ }^{1}$.

Materials design strategies requires complex data analysis that either follow data driven discovery ${ }^{20}$ or functionally driven discover ${ }^{21,22}$. In the latter desired target properties are used as an input to predict the require components that give rise to these properties. This shifts the focus to search and optimisation algorithms/ 


\begin{tabular}{|l|l|l|l|l|l|l|}
\hline Sample & Name & Stoichiometry & Phase (Pred.) & Phase (Exp.) & Lattice constant & Grain size ( $\mu$ m) \\
\hline $\mathrm{CoFeNi}_{0.5} \mathrm{Cr}_{0.5} \mathrm{Al}_{0.0}$ & $\mathrm{n}-\mathrm{Al}_{0}$ & $\mathrm{Co}_{33} \mathrm{Fe}_{33} \mathrm{Ni}_{17} \mathrm{Cr}_{17}$ & FCC & FCC & 3.57 & 692 \\
\hline $\mathrm{CoFeNi}_{0.5} \mathrm{Cr}_{0.5} \mathrm{Al}_{0.5}$ & $\mathrm{n}-\mathrm{Al}_{0.5}$ & $\mathrm{Co}_{29} \mathrm{Fe}_{29} \mathrm{Ni}_{14} \mathrm{Cr}_{14} \mathrm{Al}_{14}$ & BCC/FCC & BCC/FCC & $2.86 / 3.58$ & 206 \\
\hline $\mathrm{CoFeNi}_{0.5} \mathrm{Cr}_{0.5} \mathrm{Al}_{1.0}$ & $\mathrm{n}-\mathrm{Al}_{1.0}$ & $\mathrm{Co}_{25} \mathrm{Fe}_{25} \mathrm{Ni}_{13} \mathrm{Cr}_{13} \mathrm{Al}_{25}$ & BCC/Com & BCC/B2 & 2.89 & 196 \\
\hline $\mathrm{CoFeNi}_{0.5} \mathrm{Cr}_{0.5} \mathrm{Al}_{1.5}$ & $\mathrm{n}-\mathrm{Al}_{1.5}$ & $\mathrm{Co}_{22} \mathrm{Fe}_{22} \mathrm{Ni}_{11} \mathrm{Cr}_{11} \mathrm{Al}_{33}$ & BCC/Com & BCC/B2 & 2.88 & 316 \\
\hline
\end{tabular}

Table 1. Information on designed $\mathrm{CoFeNi}{ }_{0.5} \mathrm{Cr}_{0.5}-\mathrm{Al}_{\mathrm{x}}$ alloys, predicted phase stabilities, phases detected via $\mathrm{XRD}$, lattice parameters from $\mathrm{XRD}$, and micrograph grain sizes. The heat treatment temperatures were determined by taking the difference between the free energy of mixing of the disordered phase and an ordered $\mathrm{B} 2$ phase consisting of $\mathrm{Al} / \mathrm{Co} / \mathrm{Ni}$ (cf. Supplementary Appendix for details). A heat treatment temperature of $1,423 \mathrm{~K}(>0.8 \times$ the melting temperature of all compositions) was selected.

strategies over the use of more general materials databases. In this work, we will be using the above identified targeted related properties to optimise the $\mathrm{CoFeCrNiAl}$ composition for higher saturation magnetisation at $300 \mathrm{~K}$.

\section{Experimental section}

Synthesis. The samples were arc-melted at least thrice in the presence of a Ti getter in an Edmund Buhler Compact Arc Melter using components of $>99 \%$ purity. The samples were then cast into 6 mm diameter rods in a water-cooled copper hearth and were heat treated at $1,423 \mathrm{~K}$ for $10 \mathrm{~h}$, and quenched in water. The as-cast samples were sectioned using a Struers Secotom-50 and mounted in bakelite. Mounted samples were ground and polished to a mirror finish.

HF etching. The sample was etched with $3 \% \mathrm{HF}$ in intervals of $5 \mathrm{~s}$. Between each interval, the sample was observed under a microscope to determine the degree of etching. After etching, the samples were washed in isopropyl alcohol first, followed by washing with water.

Characterisation. Etched surface of all samples were examined with an Olympus BX51 visible light optical microscope and overview images were obtained using mosaic function in Clemex software. Grain boundaries were not clearly visible despite the etching process and the grain boundaries were enhanced by tracing over visible grain boundaries at enhanced zooms so that microstructural features are more clearly observed. A Thermo Fisher Scientific Inspect F50 $(20 \mathrm{kV})$ was used for SEM imaging. EDS line scans were carried out at sites with distinct segregation. X-ray diffraction (XRD) using a Bruker D2 phaser, with $\mathrm{Cu} \mathrm{K}_{\alpha}$ source was for XRD characterisation. From the XRD data, the lattice constants were determined using Bragg's Law. The XRD data was converted with Powdll ${ }^{23}$.

Magnetic measurements: A MPMS-3 system was used to determine the magnetisation hysteresis loops and the field cooled (FC) magnetisation as a function of temperature and applied magnetic field. From the magnetisation hysteresis loops, the coercive fields and saturation magnetisations were determined. For the experimental step size, field measurements were taken on a log-step scale, to allow for more points around the low field region, compared to the high field region, where saturation occurs. Thus between $-3 \mathrm{kA} / \mathrm{m}$ and $3 \mathrm{kA} / \mathrm{m}$ the field step size was $0.5 \mathrm{kA} / \mathrm{m}$ or less. The range was $0.04 \mathrm{kA} / \mathrm{m}$ up to $0.5 \mathrm{kA} / \mathrm{m}$ at $3 \mathrm{kA} / \mathrm{m}$. From the FC data, the Curie Temperatures were determined from the peak in the $\delta \mathrm{M} / \delta \mathrm{T}$ vs. T plots.

Image analysis: Micrograph images shown are as taken, with the optical micrographs for $n-\mathrm{Al}_{1.0}$ and $\mathrm{n}-\mathrm{Al}_{1.5}$ having the grain boundaries enhanced. This was performed by zooming in $10 \times$ onto the taken micrographs and tracing along any observed grain boundaries by hand. The contrast between the grain boundaries and the grains were very low and due to the colour fluctuations in the optical micrographs, image histogram filters were unable to distinguish the grain boundaries for an algorithmic solution. No other modifications were made to the micrographs. Particle size was determined from image analysis and are made utilising the Mathematica package ${ }^{24}$ and its built-in image analysis tools. In order to determine the precipitate size, the micrographs to be analysed are first denoised using a suitable algorithm to preserve the edges. After that, the image was auto-adjusted according to its histogram data and binarised. Edge-detection is used to determine the perimeter of the features and from this its morphological components were determined. Histogram plots of the size distribution is done in order to determine the median and mean particle size distributions.

\section{Alloy design}

Functionality driven discovery of CCAs use either ab-initio or semi-empirical approaches. Quick alloy design turnaround demands the development of faster semi-empirical approaches that can later be confirmed by $a b$ initio. Attempts to discriminate between compositions include using Hume-Rothery ${ }^{25}$ rules of valence electron concentration ${ }^{26}$, and the Miedema mode ${ }^{27}$ to investigate solid-solution stability. Other predictive semi-empirical parameter schemas attempting to obtain more accurate results also exist ${ }^{3-5,26,28-30}$. A method correlating bondlength distortion to structural stability is used in this work ${ }^{31}$, with further details in the Supplementary Appendix A. The $\mathrm{CoFeNi}_{0.5} \mathrm{Cr}_{0.5} \mathrm{Al}_{\mathrm{x}}$ composition satisfied our criteria, and so was selected. The results are compared, with good agreement, to enthalpy of mixing/valence electron predictions and are shown in Table1. 


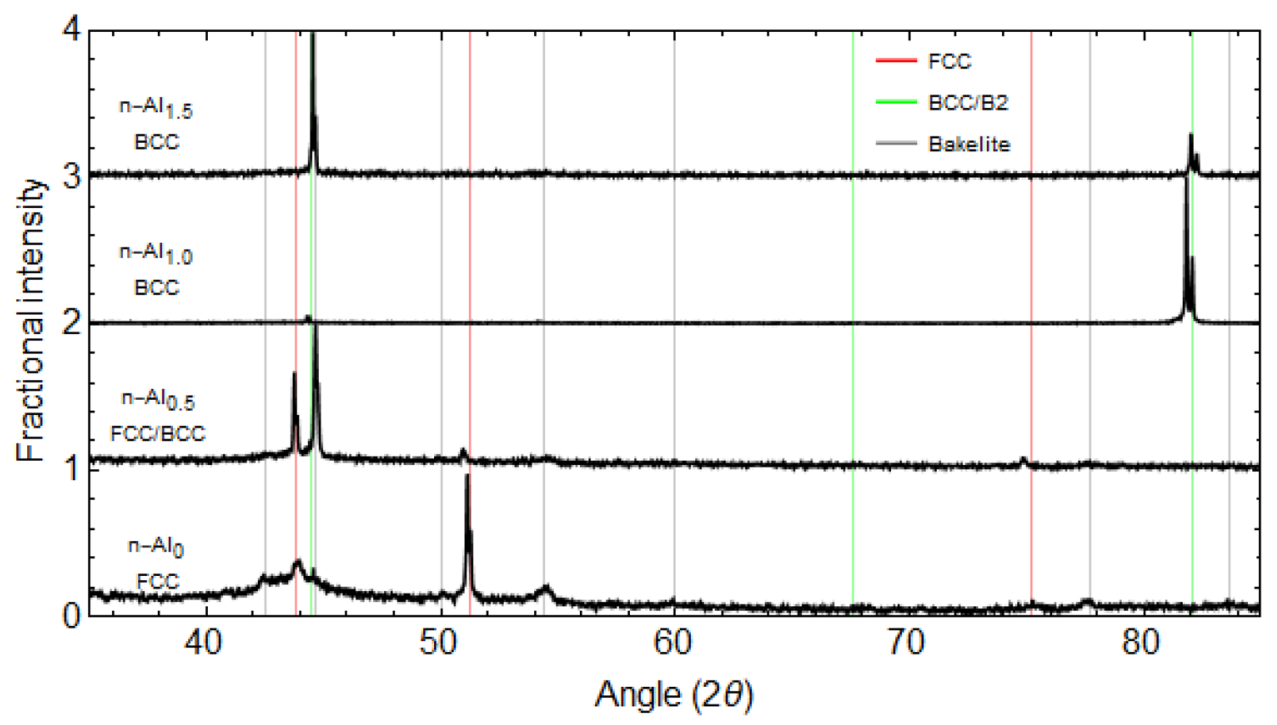

Figure 1. $\mathrm{XRD}$ data of the $\mathrm{CoFeNi}{ }_{0.5} \mathrm{Cr}_{0.5} \mathrm{Al}_{\mathrm{x}}$ samples.

\section{Results and discussion}

Phase characterisation. The samples were synthesised, heat treated, and prepared for characterisation as described in the Methodology section and initial XRD characterisation was performed. The phases present in the samples were determined from the XRD data (Fig. 1).

The $n-\mathrm{Al}_{0}$ sample has a broad peak at $2 \theta=43.8^{\circ}$, with two further peaks at $2 \theta=51.2^{\circ}$ and $77.6^{\circ}$ associated with a FCC phase (indicated as red lines). Additional peaks are observed in the sample; as the sample has been etched in HF, it was thought that there was a possibility for the Bakelite to have reacted with the etchant. In order to confirm this, an XRD trace of the $\mathrm{n}-\mathrm{Al}_{0}$ sample with a $\mathrm{Si}$ wafer covering the mounted sample was performed. The FCC peaks were found to disappear, whilst peaks at $42.5^{\circ}, 44.7^{\circ}, 50^{\circ}, 54.4^{\circ}, 60^{\circ}, 77.7^{\circ}$, and $86.3^{\circ}$ remained-this peaks are indicated by the grey lines (Determination of these are show in Supplementary Fig. A1 in the supporting information). Similar peaks are observed in the $\mathrm{n}-\mathrm{Al}_{0.5}, \mathrm{n}-\mathrm{Al}_{1.0}$, and $\mathrm{n}-\mathrm{Al}_{1.5}$ compositions although their low intensities mean that they cannot be easily distinguished in the combined plot above. For the $\mathrm{n}-\mathrm{Al}_{0.5}$ sample, it is observed that there are two phases present, a FCC phase and a BCC phase (peaks indicated by the green lines). The BCC phase has similar peak positions to the $\mathrm{BCC}$ phases observed in the $\mathrm{n}-\mathrm{Al}_{1.0}$ and $\mathrm{n}-\mathrm{Al}_{1.5}$ samples and the FCC phase has the same peak positions for the FCC phase found in the $\mathrm{n}-\mathrm{Al}_{0}$ sample. This means that the $\mathrm{Al}$ addition has started to help form the BCC phase, but the concentration is not high enough to achieve a full BCC phase. These results are in agreement with the predictions from modelling ${ }^{32}$ (Fig. 1) and with the work by Wang ${ }^{12}$ where the addition of Al promotes the BCC phase. Using Bragg's Law the lattice constant of each phase were determined and are given in Fig. 1. The lattice constants are in good agreement across the samples for the FCC phase $\left(\mathrm{n}-\mathrm{Al}_{0}\right.$ and $\left.\mathrm{n}-\mathrm{Al}_{0.5}\right)$ and the $\mathrm{BCC}$ phase $\left(\mathrm{n}-\mathrm{Al}_{0.5}, \mathrm{n}-\mathrm{Al}_{1.0}\right.$, and $\left.\mathrm{n}-\mathrm{Al}_{1.5}\right)$. The diffraction patterns suggest that the heat treated samples are highly textured as for each sample certain HKL peaks possess intensity much larger than the other peaks; this may be a residue effect from the arc-melting synthesis process leading to a preferred orientation during grain growth as a result of the cooling kinetics.

Microstructural characterisation. Figure 2 indicates the large microstructural features $(>100 \mu \mathrm{m})$ observed in the heat-treated samples for $\mathrm{n}-\mathrm{Al}_{0}, \mathrm{n}-\mathrm{Al}_{0.5}, \mathrm{n}-\mathrm{Al}_{1.0}$, and $\mathrm{n}-\mathrm{Al}_{1.5}$. The optical micrographs showed no clear distinction between the grains for the $\mathrm{n}-\mathrm{Al}_{0}$ composition, possibly because the etching process did not strongly distinguish between individual grains as they are of similar phase, requiring enhancement of the grain boundaries. Figure 2 shows the microstructural evolution as a function of $\mathrm{Al}$ addition-it is possible to quantify the sizes of the grains (or the larger grains in the case of the $\mathrm{n}-\mathrm{Al}_{0.5}$ compositions). The $\mathrm{n}-\mathrm{Al}_{0}, \mathrm{n}-\mathrm{Al}_{0.5}, \mathrm{n}-\mathrm{Al}_{1.0}$, and $\mathrm{n}-\mathrm{Al}_{1.5}$ micrographs display average grain sizes obtained from image analysis (described in the "Experimental section") of $692,206,196$, and $316 \mu \mathrm{m}$, respectively, with elongation ratios of $2.31,1.76,1.47$, and 1.32, respectively. SEM is employed to investigate if the compositional optimisation and heat treatment has resulted in the formation of secondary structures at smaller length scales.

Figure 3 shows a set of micrographs for the $\mathrm{n}-\mathrm{Al}_{\mathrm{x}}$ samples for the length scale in the region of $10 \mu \mathrm{m}$. Taken in combination with the previous micrographs of the larger structures (Fig. 2), one can observe that the grain sizes appear to decrease with $\mathrm{Al}$ addition up to $\mathrm{n}-\mathrm{Al}_{1.0}$ with precipitates appearing for $\mathrm{Al}$ additions of $\mathrm{n}-\mathrm{Al}_{0.5}$ onwards. With $\mathrm{Al}$ addition, two different phases are observed. In Fig. 3a,b light phase starts to form lath-like grains within a darker phase corresponding to the FCC and BCC phases from the XRD. For the $\mathrm{n}-\mathrm{Al}_{0.5}$ composition it may be also seen that the lath-like grains within the structure reduce in size depending on the distance away from the larger island-like structures. The literature ${ }^{12}$ suggests that the lighter lath-like structures are likely to be FeCr-rich, with the remaining elements remaining in the darker matrix. The darker $\mathrm{Al}$ containing matrix is therefore likely to be the B2 phase as these tend to be stabilised by AlCo and AlNi intermetallic pairs; and it 


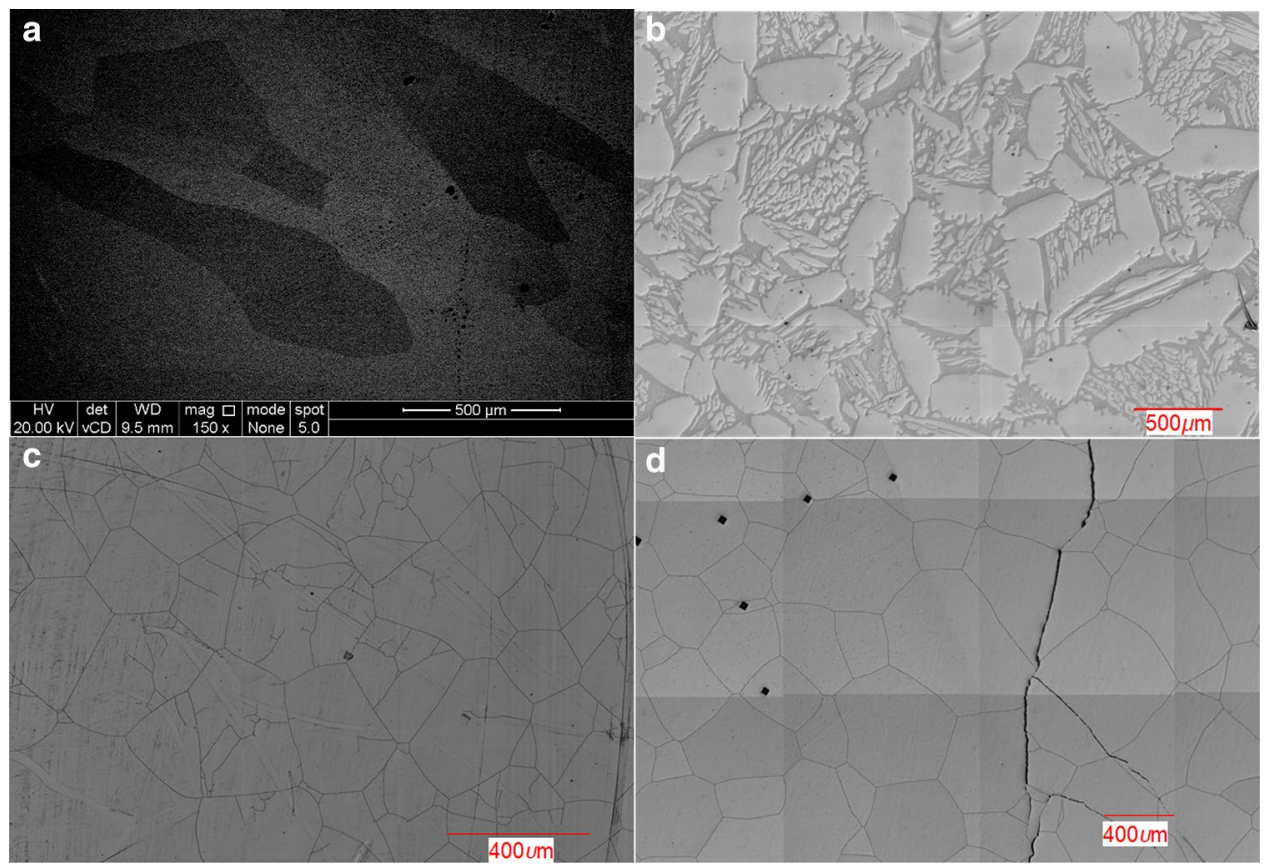

Figure 2. Enhanced micrographs of the heat-treated HF-etched $\mathrm{CoFeNi}_{0.5} \mathrm{Cr}_{0.5} \mathrm{Al}_{\mathrm{x}}$ samples, $(\mathbf{a}) \mathrm{x}=0.0$ (SEM), (b) $\mathrm{x}=0.5$ (optical microscopy), (c) $\mathrm{x}=1.0$ (optical microscopy), and (d) $\mathrm{x}=1.5$ (optical microscopy).
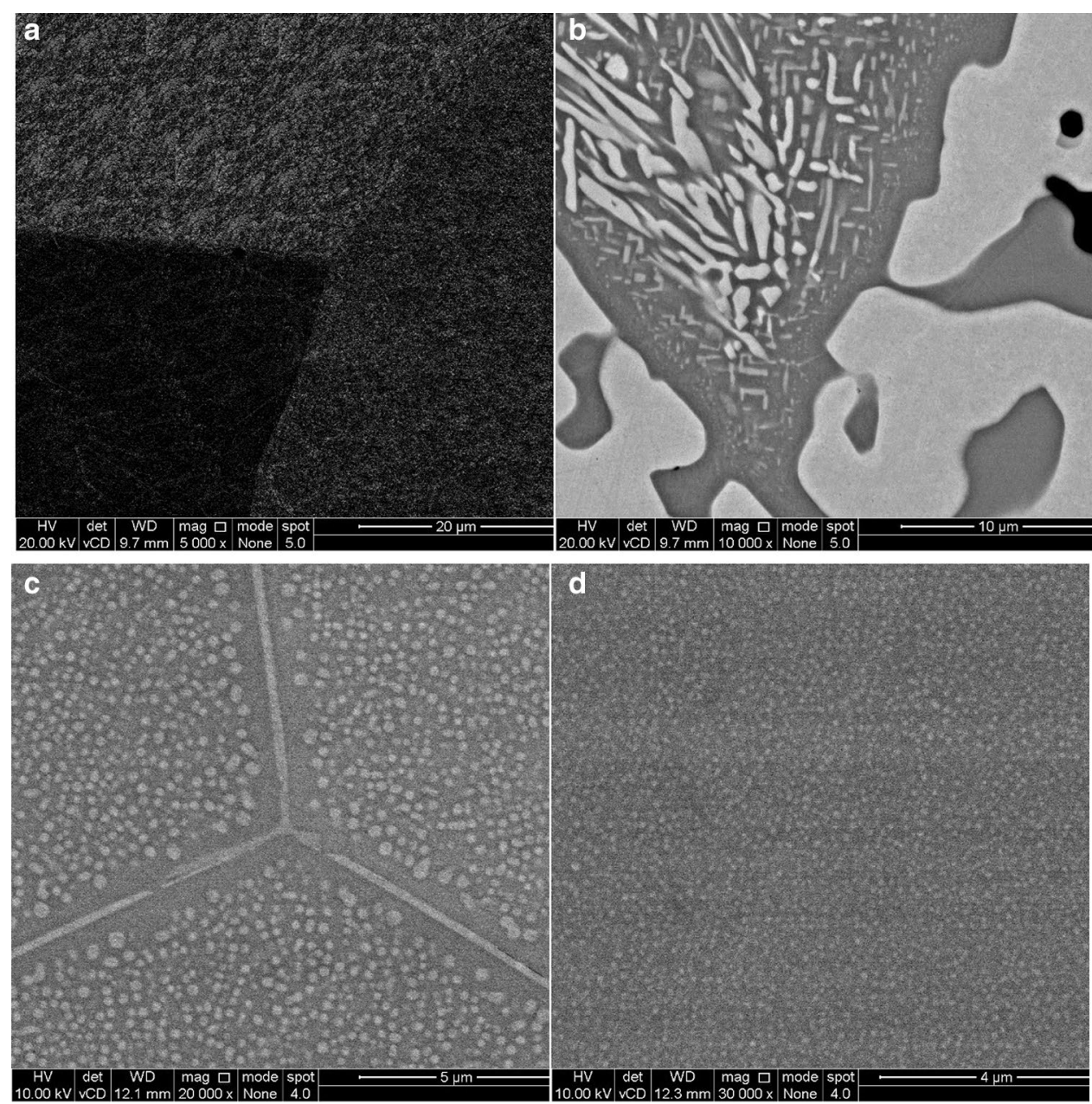

Figure 3. SEM images of the $\mathrm{CoFeNi}_{0.5} \mathrm{Cr}_{0.5} \mathrm{Al}_{\mathrm{x}}$ samples, $(\mathbf{a}) \mathrm{x}=0.0,(\mathbf{b}) \mathrm{x}=0.5,(\mathbf{c}) \mathrm{x}=1.0$, and $(\mathbf{d}) \mathrm{x}=1.5$. 


\begin{tabular}{|c|c|c|c|c|c|}
\hline \multicolumn{3}{|c|}{$\mathrm{CoCr}_{0} \mathrm{FeNi}_{05}-\mathrm{Al}_{0}$} & \multicolumn{3}{|c|}{$\mathrm{CoCr}_{0.5} \mathrm{FeNi}_{0.5}-\mathrm{Al}_{0.5}$} \\
\hline $\mathbf{a}$ & Not paired & Paired & b & Not paired & Paired \\
\hline $\mathrm{Ni}-\mathrm{Al}$ & 0 & & $\mathrm{Ni}-\mathrm{Al}$ & & 0.91 \\
\hline $\mathrm{Cr}-\mathrm{Al}$ & 0 & & $\mathrm{Cr}-\mathrm{Al}$ & -0.93 & \\
\hline $\mathrm{Cr}-\mathrm{Ni}$ & -0.28 & & $\mathrm{Cr}-\mathrm{Ni}$ & $-1 . \overline{04}$ & \\
\hline Co-Al & 0 & & Co-Al & & 0.75 \\
\hline $\mathrm{Co}-\mathrm{Ni}$ & & 0.23 & $\mathrm{Co}-\mathrm{Ni}$ & & 0.87 \\
\hline $\mathrm{Co}-\mathrm{Cr}$ & & 1.1 & $\mathrm{Co}-\mathrm{Cr}$ & -0.77 & \\
\hline $\mathrm{Fe}-\mathrm{Al}$ & 0 & & $\mathrm{Fe}-\mathrm{Al}$ & -0.99 & \\
\hline $\mathrm{Fe}-\mathrm{Ni}$ & -0.11 & & $\mathrm{Fe}-\mathrm{Ni}$ & -1.08 & \\
\hline $\mathrm{Fe}-\mathrm{Cr}$ & & 0.33 & $\mathrm{Fe}-\mathrm{Cr}$ & & 1.03 \\
\hline $\mathrm{Fe}-\mathrm{Co}$ & -0.0 & & $\mathrm{Fe}-\mathrm{Co}$ & -0.7 & \\
\hline
\end{tabular}

\begin{tabular}{|c|c|c|c|c|c|}
\hline \multicolumn{3}{|c|}{$\mathrm{CoCr}_{0.5} \mathrm{FeNi}_{0.5}-\mathrm{Al}_{1.0}$} & \multicolumn{3}{|c|}{$\mathrm{CoCr}_{0.5} \mathrm{FeNi}_{0.5}-\mathrm{Al}_{1.5}$} \\
\hline C & Not paired & Paired & d & Not paired & Paired \\
\hline $\mathrm{Ni}-\mathrm{Al}$ & & 0.8 & $\mathrm{Ni}-\mathrm{Al}$ & & 0.95 \\
\hline $\mathrm{Cr}-\mathrm{Al}$ & -0.87 & & $\mathrm{Cr}-\mathrm{Al}$ & -0.92 & \\
\hline $\mathrm{Cr}-\mathrm{Ni}$ & -0.8 & & $\mathrm{Cr}-\mathrm{Ni}$ & -0.93 & \\
\hline Co-Al & & 0.68 & Co-Al & & 0.97 \\
\hline $\mathrm{Co}-\mathrm{Ni}$ & & 0.74 & $\mathrm{Co}-\mathrm{Ni}$ & & 1.01 \\
\hline $\mathrm{Co}-\mathrm{Cr}$ & -0.73 & & $\mathrm{Co}-\mathrm{Cr}$ & -1.01 & \\
\hline $\mathrm{Fe}-\mathrm{Al}$ & -0.53 & & $\mathrm{Fe}-\mathrm{Al}$ & -0.8 & \\
\hline $\mathrm{Fe}-\mathrm{Ni}$ & $-0,79$ & & $\mathrm{Fe}-\mathrm{Ni}$ & -0.75 & \\
\hline $\mathrm{Fe}-\mathrm{Cr}$ & & 0.56 & $\mathrm{Fe}-\mathrm{Cr}$ & & 0.86 \\
\hline $\mathrm{Fe}-\mathrm{Co}$ & $-0,74$ & & $\mathrm{Fe}-\mathrm{Co}$ & $-0,76$ & \\
\hline
\end{tabular}

Figure 4. Elemental populations of each EDS line scan was plotted against one another to determine their binary pairing preferences for $(\mathbf{a}) \mathrm{n}-\mathrm{Al}_{0},(\mathbf{b}) \mathrm{n}-\mathrm{Al}_{0.5},(\mathbf{c}) \mathrm{n}-\mathrm{Al}_{1.0}$ and $(\mathbf{d}) \mathrm{n}-\mathrm{Al}_{1.5}$. The plots show the gradient for each pair, with positive gradients suggesting pairing and negative gradients suggesting segregation. The plots suggest increased elemental partitioning for $\mathrm{n}-\mathrm{Al}_{0.5}$.

may be inferred from (1) The distribution of varied particles sizes across the sample, and (2) The selected heat treatment temperature argument earlier that the $\mathrm{FeCr}$ (likely BCC structure) is precipitated upon heat treatment.

On further $\mathrm{Al}$ additions (as in $\mathrm{n}-\mathrm{Al}_{1.0}$ ) nanoparticles are observed to be embedded into a matrix (as shown in Fig. 3c) which are homogenously distributed within each grain and circular in shape. In terms of precipitate shapes, for a given precipitate volume a spherical shape has the highest strain energy while a thin plate has the lowest strain energy (this is because almost all metals are mechanically anisotropic) ${ }^{18,33,34}$. As the shape of a precipitate is controlled by the balance between the interfacial energy and the elastic strain energy of the system (i.e. $L=\frac{\varepsilon^{2} C_{44} r}{s}$ where $\dot{\varepsilon}$ is the lattice misfit, $\mathrm{C}_{44}$ is the shear modulus, $r$ the particle size, and $s$ the interfacial energy), this implies that the interfacial energy in the system is high enough to balance the presence of the coherent spherical shapes ${ }^{35-37}$. This is likely due to the $\mathrm{n}-\mathrm{Al}_{0}$ composition possessing high interfacial energies as large amounts of coherency stresses are required to supress solid solution compositional gradients (from the multiple alloy components) $)^{38,39}$.

Noting again that $\Delta H$ of $\mathrm{Al}-\mathrm{Co}$ and $\mathrm{Al}-\mathrm{Ni}$ are much higher than the other binary components, $\mathrm{Al}$ addition to the $\mathrm{n}-\mathrm{Al}_{0}$ system therefore provides a driving force for segregation. Although segregation is generally noted to reduce the interfacial free energy, in this multicomponent system both competing extremes of $\Delta H$ are presents: (1) Very negative $\Delta H$ values $(<-15)$ that drive segregation, and (2) Near-ideal $\Delta H$ values $(0>\Delta H>-5)$ that lead to compositional gradients. Additionally, magnetic frustration between interfacial $\mathrm{Fe}-\mathrm{Cr}$ is expected to increase its energy ${ }^{40}$, which may be reflected in the magnetic properties of the nanoprecipitate containing $\mathrm{n}-\mathrm{Al}_{1.0}$ and $\mathrm{n}-\mathrm{Al}_{1.5}$ compositions. By corollary, it may be expected for the $\mathrm{FeCr}$ precipitates to reduce in size with $\mathrm{Al}$ addition as less $\mathrm{Fe}$ and $\mathrm{Cr}$ are available in the system; this is in line with our experimental data. In order to further test this inference that the phases are split into a FeCr-rich and a AlCoNi phase, we quantify the nanoparticle size and the elemental mixing in the system through EDS analysis.

As the size of the precipitates were much smaller than the spot size of the EDS, an exact elemental distribution could not be obtained. However, analysis was performed utilising a line scan; analysis of elemental pair fluctuations (cf. Fig. 4) reveal that the $\mathrm{AlCr}$, $\mathrm{AlFe}, \mathrm{CrCo}, \mathrm{CrNi}$, FeCo, and FeNi pairs are not positively correlated with one another. Conversely, $\mathrm{AlCo}, \mathrm{AlNi}, \mathrm{CrFe}$, and $\mathrm{CoNi}$ pairs are strongly linked to one another, suggesting that the compositional mixture is strongly driven by the $\mathrm{Al}$ pairs, hence influenced heavily by $\mathrm{Al}$ additions. Similar analysis was also performed on the other compositions $\left(\mathrm{n}-\mathrm{Al}_{0.5}, \mathrm{n}-\mathrm{Al}_{1.5}\right)$ which showed similar pairing similarities with the $\mathrm{n}-\mathrm{Al}_{1.0}$ composition. Unsurprisingly, a pair analysis of the enthalpy of mixing values shows that for all the available pairs, the AlCo and AlNi pairs possess the most negative enthalpies of mixing ( -19 and $-22 \mathrm{~kJ} /$ $\mathrm{mol}$ ); other than the binary compounds, AlCoNi stoichiometries have been reported in literature ${ }^{41}$. These results are in excellent agreement with the hypothesis that the AlCoNi and $\mathrm{FeCr}$ are segregated. 

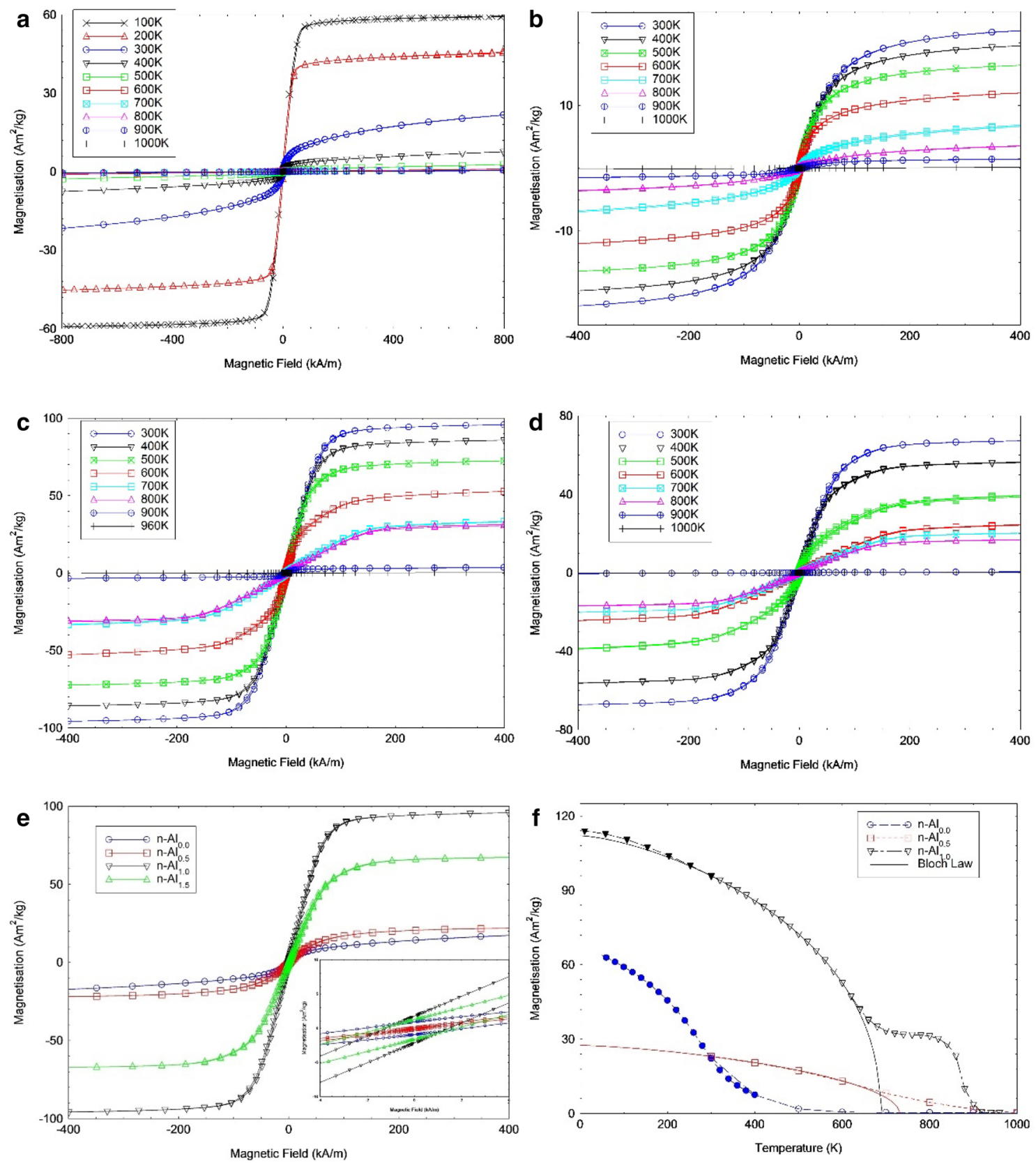

Figure 5. Magnetisation hysteresis loops for the heat treated $\mathrm{CoFeNi}{ }_{0.5} \mathrm{Cr}_{0.5} \mathrm{Al}_{\mathrm{x}}$ samples as a function of temperature, for $(\mathbf{a}) \mathrm{n}-\mathrm{Al}_{0},(\mathbf{b}) \mathrm{n}-\mathrm{Al}_{0.5},(\mathbf{c}) \mathrm{n}-\mathrm{Al}_{1.0}$, (d) $\mathrm{n}-\mathrm{Al}_{1.5}$ measured up to $400 \mathrm{kA} / \mathrm{m},(\mathbf{e})$ Comparison of all compositions hysteresis loops at $300 \mathrm{~K}$. Inset: Zoom-in of the hysteresis loops around $0 \mathrm{kA} / \mathrm{m}$ to focus on the coercive field, and (f) M-T curves at $400 \mathrm{kA} / \mathrm{m}$ extrapolated using Bloch's law to low temperatures from the hysteresis loop data, open shapes represent the high temperature data $(>300 \mathrm{~K})$ and closed shapes represent the low temperature data $(<400 \mathrm{~K})$. The solid lines are the Bloch law fit to the high temperature data.

Image analysis as outlined in the Experimental Section was performed to determine the size distribution of the nanoprecipitates. $\mathrm{n}-\mathrm{Al}_{0.5}$ has nanoprecipitates which are not uniformly distributed and its analysis is described in the Appendix. The average (mean) size of the precipitates appears to change from $245 \mathrm{~nm}$ (length) for the $\mathrm{n}-\mathrm{Al}_{0.5}$ sample to 180 , and $120 \mathrm{~nm}$ (diameter) for the $\mathrm{n}-\mathrm{Al}_{1.0}$, and $\mathrm{n}-\mathrm{Al}_{1.5}$ alloys. The size of the precipitates thus decreases as a function of $\mathrm{Al}$ addition. Figure 1 provides an overview of the samples studied, along with the structural parameters determined from XRD and SEM. The experimental observations of the variation of the particle sizes with the $\mathrm{n}-\mathrm{Al}_{0.5}, \mathrm{n}-\mathrm{Al}_{1.0}$, and $\mathrm{n}-\mathrm{Al}_{1.5}$ are in agreement with our inference of $\mathrm{FeCr}$ and $\mathrm{AlCoNi}$ segregation. We next perform and discuss the magnetic characterisation of the samples in order to validate the hypothesis of increased magnetisation from the alloy design procedure.

Correlating phase with magnetic behaviour. Figure 5 shows the set of hysteresis loops that have been obtained from the various heat-treated samples utilising the MPMS-3 SQUID. From these loops the total mag- 

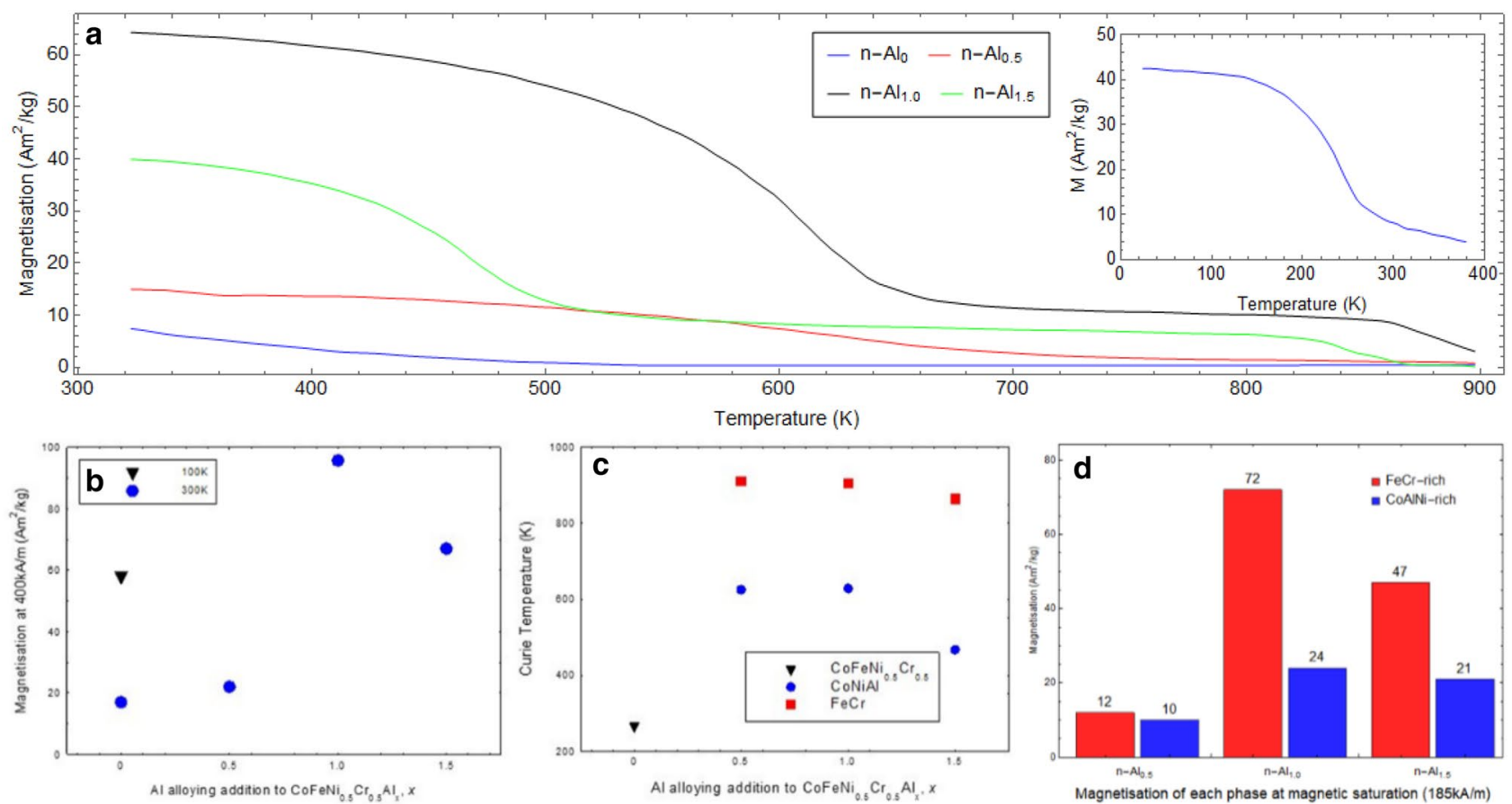

Figure 6. (a) Field cooled magnetisation of $\mathrm{CoFeNi}_{0.5} \mathrm{Cr}_{0.5} \mathrm{Al}_{\mathrm{x}}$ samples with an applied field of $48 \mathrm{kA} / \mathrm{m}$ for $300 \mathrm{~K} \leq \mathrm{T} \leq 1,000 \mathrm{~K}$. Inset: Low Temperature Field cooled magnetisation of $\mathrm{CoFeNi}_{0.5} \mathrm{Cr}_{0.5}$ sample for $50 \mathrm{~K} \leq \mathrm{T} \leq 400 \mathrm{~K}$, (b) Magnetisation at $100 \mathrm{~K}\left(\mathrm{n}-\mathrm{Al}_{0}\right)$ and $300 \mathrm{~K}\left(\mathrm{n}-\mathrm{Al}_{0}, \mathrm{n}-\mathrm{Al}_{0.5}, \mathrm{n}-\mathrm{Al}_{1.0}\right.$ and $\left.\mathrm{n}-\mathrm{Al}_{1.5}\right)$, (c) Curie Temperature as a function of $\mathrm{Al}$ concentration, and (d) Magnetisation of each phase at saturation $(185 \mathrm{kA} / \mathrm{m})$.

netisation at $400 \mathrm{kA} / \mathrm{m}$ was determined as a function of temperature. From Fig. 5, it is seen that all the samples have soft magnetic properties, with coercive fields less than $2.5 \mathrm{kA} / \mathrm{m}$ at $300 \mathrm{~K}$ (Fig. 5e inset). The $\mathrm{n}-\mathrm{Al}_{0}$ sample has a large paramagnetic component in addition to a magnetic component (Fig. 5a), as the magnetisation does not saturate at high applied magnetic field. From low temperature measurements (100-400 K), the loops become fully saturated at $200 \mathrm{~K}$, with a saturation magnetisation of $58 \mathrm{Am}^{2} / \mathrm{kg}$ at $400 \mathrm{kA} / \mathrm{m}$ measured and $100 \mathrm{~K}$.

From these figures, (cf. Figs. 5, 6a), it is observed that with the addition of $\mathrm{Al}$ to $\mathrm{n}-\mathrm{Al}_{0}$, the total magnetisation at $400 \mathrm{kA} / \mathrm{m}$ and $300 \mathrm{~K}$ increases with $\mathrm{Al}$ concentration from 22 to $96 \mathrm{Am}^{2} / \mathrm{kg}$, respectively for $\mathrm{n}-\mathrm{Al}_{0.5}$, and $\mathrm{n}-\mathrm{Al}_{1.0}$ respectively, and then decreases to $67 \mathrm{Am}^{2} / \mathrm{kg}$ for $\mathrm{n}-\mathrm{Al}_{1.5}$. Although precipitates are observed in $\mathrm{n}-\mathrm{Al}_{0.5}$ onwards (cf. Fig. 3), the median particle size changes from 760, 184, and $100 \mathrm{~nm}$, respectively as more $\mathrm{Al}$ is added. This is close to one order of magnitude reduction in median particle size, which suggests that the presence of the FeCr nanoparticles in the $\mathrm{n}-\mathrm{Al}_{1.0}$ and $\mathrm{n}-\mathrm{Al}_{1.5}$ samples has an influence on the larger magnetisations observed, as the $\mathrm{n}-\mathrm{Al}_{0.5}$ samples possess much lower magnetisations at $300 \mathrm{~K}, 22 \mathrm{Am}^{2} / \mathrm{kg}$.

Following our previous inference that $\mathrm{AlCoNi}$ and $\mathrm{FeCr}$ are separated from one another, we note that the $\mathrm{Fe}: \mathrm{Cr}(2: 1)$ ratios do not change with increasing $\mathrm{Al}$ addition. Although $\mathrm{Fe}: \mathrm{Cr}$ ratios do not change with $\mathrm{Al}$ addition, the composition of the matrix does change with Al addition. Referring to Wang et al.'s AlCoNi ternary phase diagrams 41 (assuming that the compositional segregation is done well), the phase composition of the matrix shifts from $L 1_{2}$ for $n-\mathrm{Al}_{0}$ to $\mathrm{Ll}_{2}+\mathrm{B}_{2}, \mathrm{~B}_{2}$, and $\mathrm{B}_{2}$ as the $\mathrm{Al}$ content increases $\left(\mathrm{L}_{2}\right.$ and $\mathrm{B}_{2}$ are the ordered form of the FCC and BCC phases, respectively). Taking together the analysis of the AlCoNi and FeCr phase diagrams, these observations appear to be in good agreement with our XRD characterisation, and our pre-synthesis predictions of the alloy's phases (i.e. FCC $\rightarrow$ FCC $+\mathrm{BCC} \rightarrow \mathrm{BCC} \rightarrow \mathrm{BCC}$ ) as current semi-empirical models do not allow for the prediction of the ordered FCC/BCC variants (e.g. $\mathrm{L}_{12}, \mathrm{~B}_{2}$ etc.).

This however, indicates that increasing the $\mathrm{Al}$ stoichiometric ratio increases $\mathrm{B} 2$ stability, which leads to a corresponding increase in Curie temperature and in saturation magnetisation for fully formed NPs. The increase magnetisation of the $\mathrm{BCC} / \mathrm{B} 2$ phase (on a phase transition from FCC stability on $\mathrm{Al}$ addition) has been previously noted in the literature ${ }^{42}$, which may be driven by increased magnetic ordering, as noted previously ${ }^{13,43}$. However, it is not clear that the changes in magnetic behaviour are solely related to the BCC/B2 structure as extrapolating the MT curves for the $\mathrm{n}-\mathrm{Al}_{0.5}$ sample using Bloch's law gives a magnetisation of $27 \mathrm{Am}^{2} / \mathrm{kg}$ at $5 \mathrm{~K}$ (cf. Fig. 5f), which is lower than the measured magnetisation of $66 \mathrm{Am}^{2} / \mathrm{kg}$ at $5 \mathrm{~K}$ for the $\mathrm{n}-\mathrm{Al}_{0}$ sample. The pronounced drop in $\mathrm{M}_{\mathrm{s}}$ with $\mathrm{Al}$ addition between $\mathrm{n}-\mathrm{Al}_{0}$ and $\mathrm{n}-\mathrm{Al}_{0.5}$ can be ascribed to the addition of paramagnetic $\mathrm{Al}$. However, $\mathrm{n}$-Al0 sees a faster drop in Ms in comparison to n-Al0.5 past its Tc $(265 \mathrm{~K})$. At temperatures above $295 \mathrm{~K}$, the magnetisation of $\mathrm{n}$-Al0 is lower than $\mathrm{n}-\mathrm{Al} 0.5,19 \mathrm{vs} .23 \mathrm{Am}^{2} / \mathrm{kg}$ at $300 \mathrm{~K}$. Yet, a significant FM component remains at $\mathrm{T}>265 \mathrm{~K}$ in $\mathrm{n}-\mathrm{Al}_{0}$ - this may be due to the near-ideal nature of the compositions, which is discussed further below. This variation in magnetic behaviour between $n-\mathrm{Al}_{0}$ and $\mathrm{n}-\mathrm{Al}_{0.5}$ should therefore be attributed to the increase in the alloying addition of non-magnetic $\mathrm{Al}$ to the composition. Moreover, $\mathrm{M}_{\mathrm{s}}$ reduction from $\mathrm{n}-\mathrm{Al}_{1.0}$ to $\mathrm{n}-\mathrm{Al}_{1.5}$ is $29 \mathrm{Am}^{2} / \mathrm{kg}$, which is an order of magnitude larger than that of the volumetric decrease in $\mathrm{FeCr}$ alloying elements. This clearly means that other factors other than the FCC to BCC transition affects magnetisation 
behaviour here. Therefore, one might expect the change in magnetic properties to be caused by a combination of (1) Elemental segregation from Al addition and the resultant interaction between the AlCoNi matrix and the FeCr precipitates; (2) The decreasing particle size of the FeCr precipitates; and (3) The degree of disorder within the newly formed phases due to its non-ideal nature.

The magnetisation as a function of temperature $(\mathrm{M}-\mathrm{T})$ data from 1,000 to $300 \mathrm{~K}$ (from 400 to $100 \mathrm{~K}$ for $\mathrm{n}-\mathrm{Al}_{0}$ ) is shown in Fig. 6a (inset). It is observed that the $\mathrm{n}-\mathrm{Al}_{0}$ sample has a broad transition which starts at $\sim 580 \mathrm{~K}$, reaching saturation at $\sim 150 \mathrm{~K}$. The Curie Temperature $\left(\mathrm{T}_{\mathrm{c}}\right)$ for $\mathrm{CoFeNi}_{0.5} \mathrm{Cr}_{0.5}$ is $265 \mathrm{~K}$ (obtained by taking the $\mathrm{M}-\mathrm{T}$ derivative). The broad transition may be due to the near-ideal nature of the solid solution, coupled with the heat treatment of the alloys leading to segregation within the system. Due to this, there is the possibility of enrichment within the microstructure-this could explain the broadness in the distribution in the $\mathrm{T}_{\mathrm{C}}$ from $\mathrm{Cr}$ enriched/depleted regions that are nearly identical to one another. We can therefore hypothesise that chromium inhomogeneity through the material leads to a wide distribution of magnetic compositions of different Tc, explaining the long tail in the M-T curve and measurable FM response at temperatures higher than $265 \mathrm{~K}$.

Comparing the calculated Curie Temperature with those found in literature ${ }^{7,13}$, it lies within the $\operatorname{CoFeNiCr}_{\mathrm{x}}$ system, where for $\mathrm{x}=0.9$ and 0.7 the $\mathrm{T}_{\mathrm{c}}=300$ and $200 \mathrm{~K}$ respectively. Kormann et al'. $\mathrm{s}^{8}$ theoretical calculations shows that $\mathrm{M}_{\mathrm{s}}$ experiences a $68 \%$ increase from 0.55 to $0.93 \mu \mathrm{B}\left(54-91 \mathrm{Am}^{2} / \mathrm{kg}\right)$ in $\mathrm{CoFeNiCr}_{\mathrm{x}}$ on $\mathrm{Cr}_{\mathrm{x}}$ reduction from $\mathrm{x}=1$ to $\mathrm{x}=0.5$ and an increase in $\mathrm{T}_{\mathrm{c}}$ from 119 to $418 \mathrm{~K}$. However, Kormann's CoFeNiCr ${ }_{0.5}-\mathrm{M}_{\mathrm{s}}$ of $91 \mathrm{Am}^{2} /$ $\mathrm{kg}$ is higher than our synthesised $\mathrm{n}-\mathrm{Al}_{0}$ sample $\left(58 \mathrm{Am}^{2} / \mathrm{kg}\right.$, taken from $\mathrm{M}-\mathrm{H}$ loop at $400 \mathrm{kA} / \mathrm{m}$ and $\left.100 \mathrm{~K}\right)$. The difference in these values can be explained by the reduction in Ni content. Overall, experimental and simulation results from literature are in good agreement with the results presented here for the $\mathrm{n}-\mathrm{Al}_{0}$ sample.

As the magneto-thermal analysis in the region from 50 up to $1,000 \mathrm{~K}$ shows a single magnetic transition of the $\mathrm{n}-\mathrm{Al}_{0}$ sample at $265 \mathrm{~K}$, and considering that microstructural and structural analysis at $\mathrm{RT}$ show no evidence of compositional segregation of $\mathrm{FeCr}$, it is assumed that $\mathrm{Al}$ addition triggers the phase separation into ferromagnetic-FeCr-rich-nanoparticles and a CoNiAl-rich-matrix. Therefore, the magnetic properties of the $\mathrm{n}-\mathrm{Al}_{\mathrm{x}}(\mathrm{x} \geq 0.5)$ are linked to the nanoparticles nucleation, growth, and assembly. In order to investigate these properties, we take a closer look at the magnetic data to compare these to our initial suppositions on the link between the physical microstructure of the alloys and its functional magnetic properties.

Magnetic properties of the phases: $T_{c^{*}}$. From the magnetisation-temperature data (Fig. 6), it is observed that the $\mathrm{n}-\mathrm{Al}_{0.5}, \mathrm{n}-\mathrm{Al}_{1.0}$, and $\mathrm{n}-\mathrm{Al}_{1.5}$ samples all have two temperature transitions, which is in agreement with the hypothesis that the microstructure is divided into AlCoNi and FeCr-rich phases. The first transition occurs between 550 and $650 \mathrm{~K}$, and is a broad transition. The second transition occurs between 860 and $930 \mathrm{~K}$, and is a sharper transition. These transitions may be linked to the phases observed in the different samples. We first discuss the possible attribution of the 900-1,050 K transition to the FeCr-rich phase and later the 500-650 K to AlCoNi-rich phase.

A comparison with the literature suggests that $\mathrm{FeCr}$ possesses a $\mathrm{T}_{\mathrm{c}}$ between $900-1,050 \mathrm{~K}$ for $\mathrm{Cr}<0.25^{44}$. $\mathrm{FeCr} \mathrm{T}_{\mathrm{c}}$ dependence on $\mathrm{Cr}$ addition is also corroborated by other references, showing a slight increase from $\mathrm{Fe}$ $\mathrm{T}_{\mathrm{c}}(1046 \mathrm{~K})$ with less than $5 \% \mathrm{Cr}$, following by decreasing $\mathrm{T}_{\mathrm{c}}$ as $\mathrm{Cr}$ percentage increases ${ }^{32}$. Shafranovsky et al. ${ }^{45}$ studied different concentrations of $\mathrm{FeCr}$ foils and nanoparticles, and found that the $\mathrm{T}_{\mathrm{c}}$ of $\mathrm{Fe}_{66} \mathrm{Cr}_{33}$ nanoparticles was $843 \mathrm{~K}$. This value agrees with our observed transitions; thus the addition of Al to the system has shifted one of the Curie temperatures to higher values through inducing elemental segregation in the system. The $\mathrm{T}_{\mathrm{c}}$ of the $\mathrm{FeCr}$ phase decreases with increasing $\mathrm{Al}$ concentration (Fig. 6c). Generally, Cr reduction (here due to $\mathrm{Al}$ addition) in $\mathrm{FeCr}$ is associated with increasing $\mathrm{T}_{\mathrm{c}}$, which is not our observation. Although the nanoparticles can be inferred to be $\mathrm{FeCr}$ from our pair analysis, it is important to note that in all compositions the Fe:Cr ratio is constant at 1:0.5-this means that any change in $\mathrm{T}_{\mathrm{c}}$ should be independent of the compositional change. However the $\mathrm{FeCr}$ $\mathrm{T}_{\mathrm{c}}$ drops from $\sim 912 \mathrm{~K}, \sim 900 \mathrm{~K}$, and $\sim 862 \mathrm{~K}$ from $\mathrm{n}-\mathrm{Al}_{0.5}$ to $\mathrm{n}-\mathrm{Al}_{1.0}$ to $\mathrm{n}-\mathrm{Al}_{1.5}$. This is a $60 \mathrm{~K}$ drop for a $3 \%$ reduction in Cr alloy content. Taking a linear fit from Shafranovsky et al.'s data ${ }^{45}$ suggests an increase in $\mathrm{T}_{\mathrm{c}}$ of $18 \mathrm{~K}$ for a 3\% decrease in $\mathrm{Cr}$ content-this is in the other direction that we would expect from FeCr effects. The trend we observe is also consistent with $\mathrm{Al}$ addition, meaning that experimental error in terms of synthesis and alloy weight-out can be discounted. The decrease in $\mathrm{T}_{\mathrm{c}}$, we infer to be related to two possible reasons: (1) The size of the $\mathrm{FeCr}$ grains/particles decreases with increasing Al concentration (Fig. 3) and this may cause the decrease in the $\mathrm{T}_{\mathrm{c}}$. (2) Due to small changes in stoichiometric either in the matrix or the precipitates.

Point 2 is explained by the stoichiometric ratios of Al:Co $(0,0.5,1$, and 1.5) and $\mathrm{Al}: \mathrm{Ni}(0,1,2$, and 3$)$ for $\mathrm{n}-\mathrm{Alx}(\mathrm{x}: 0,0.5,1$, and 1.5$)$ and the binary enthalpy of mixings $\mathrm{Al}-\mathrm{Cr}(-10 \mathrm{~kJ} / \mathrm{mol}), \mathrm{Al}-\mathrm{Co}(-19 \mathrm{~kJ} / \mathrm{mol}), \mathrm{Al}-\mathrm{Ni}$ $(-22 \mathrm{~kJ} / \mathrm{mol}), \mathrm{Cr}-\mathrm{Ni}(-7 \mathrm{~kJ} / \mathrm{mol}), \mathrm{Cr}-\mathrm{Co}(-4 \mathrm{~kJ} / \mathrm{mol})$, and $\mathrm{Fe}-\mathrm{Cr}(-1 \mathrm{~kJ} / \mathrm{mol})$. Given $\mathrm{Co} \mathrm{Fe} \mathrm{Cr} \mathrm{Ni} \mathrm{Al} \mathrm{alloying}$ additions, the presence of $\mathrm{Al}$ is the limiting factor as $\mathrm{Al}-\mathrm{Co}$ and $\mathrm{Al}-\mathrm{Ni}$ have the most negative enthalpies of mixing. When there is not enough $\mathrm{Al}$ to pair with $\mathrm{Ni}$ and $\mathrm{Co}$, the $\mathrm{Ni}-\mathrm{Cr}$ and $\mathrm{Co}-\mathrm{Cr}$ pairs can form since they are the more negative compared to $\mathrm{Fe}-\mathrm{Cr}$. When there is enough $\mathrm{Al}$, the phases are fully segregated. However, with excess $\mathrm{Al}, \mathrm{Al}-\mathrm{Cr}$ pairs can form. A reduction in $\mathrm{FeCr} \mathrm{T}_{\mathrm{C}}$ can therefore be explained by $\mathrm{Al}$ interacting with the FeCr-rich phase as excess $\mathrm{Al}$ is added to the system. This appears to agree with the experimental results as $\mathrm{T}_{\mathrm{C}}$ initially rises with $\mathrm{Al}$ addition but then decreases.

For the 500-650 K transition, the temperature ranges over which it occurs decreases with the increase of $\mathrm{Al}$ addition from $\mathrm{n}-\mathrm{Al}_{0.5}$ to $\mathrm{n}-\mathrm{Al}_{1.5}$; the $\mathrm{n}-\mathrm{Al}_{0.5}$ possesses a broad transition of $\sim 215 \mathrm{~K}$ compared to $80-100 \mathrm{~K}$ for the $\mathrm{n}-\mathrm{Al}_{1.0}$ and $\mathrm{n}-\mathrm{Al}_{1.5}$ samples. From the literature it is possible to piece together, different $\mathrm{T}_{\mathrm{c}}$ for different ratios of CoNiAl. From Saito's paper ${ }^{46}$, they studied $\mathrm{Co}-\mathrm{Al}$ ribbons with different concentrations of $\mathrm{Ni}$ and found that a non-equilibrium BCC phase of $(\mathrm{Co}, \mathrm{Ni}) \mathrm{Al}$ was achieved with a Curie Temperature between $700 \mathrm{~K}(0 \% \mathrm{Ni})$ to $300 \mathrm{~K}(40 \% \mathrm{Ni})$. Other examples of binary alloy $\mathrm{T}_{\mathrm{c}}$ are $\mathrm{Al}_{0.25} \mathrm{Ni}_{0.75}(420 \mathrm{~K}), \mathrm{Al}_{56} \mathrm{Co}_{44}(180 \mathrm{~K})$, and $\mathrm{Al}_{42} \mathrm{Co}_{58}(426 \mathrm{~K})$, all of which tend to be much lower than $900 \mathrm{~K}$. This is backed up by Ikedia's paper ${ }^{47}$, which on average shows that 

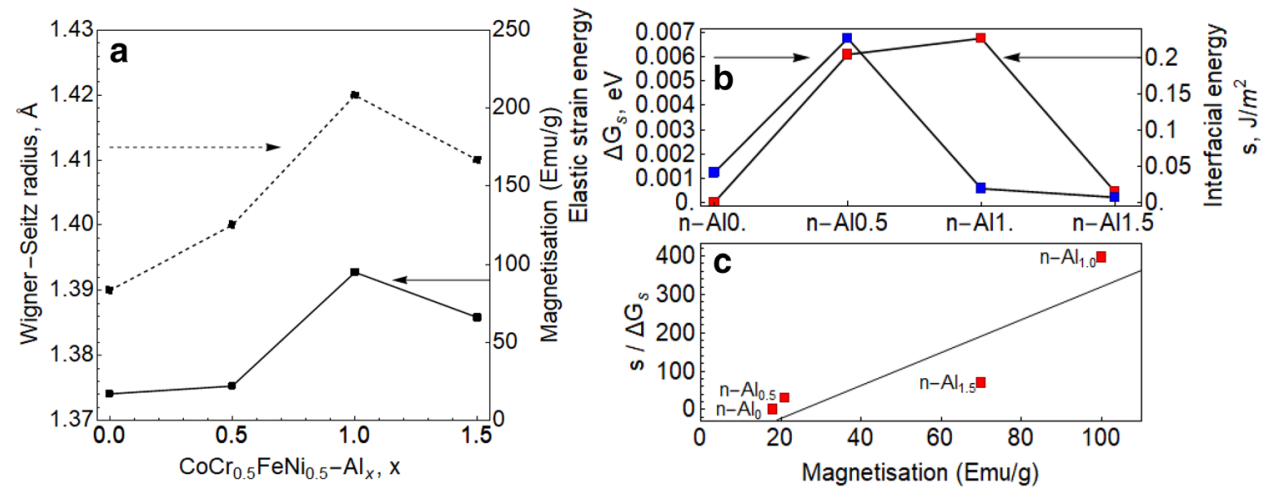

Figure 7. (a) Comparison of Wigner-Seitz radius determined from XRD phase fractions and lattice parameters with magnetisation at $400 \mathrm{kA} / \mathrm{m}$ values, (b) Elastic strain energy, $\Delta \mathrm{G}_{\mathrm{s}}$ and interfacial energy, s plotted as a function of $\mathrm{Al}$ addition showing excess $\mathrm{s}$ for $\mathrm{n}-\mathrm{Al}_{1}$, and $(\mathbf{c}) \mathrm{s} / \Delta \mathrm{G}_{\mathrm{s}}$ ratio plotted against magnetisation at 400 $\mathrm{kA} / \mathrm{m}$. The line is present as a guide for the eye.

an increase in the Ni content into CoAl decreases the Curie Temperature, with $20 \%$ Ni having a Curie Temperature of $508 \mathrm{~K}$. The concentration of the $\mathrm{Ni}$ in this work is between 16.5 and $25 \%$ depending on the $\mathrm{Al}$ concentration. From Saito's paper this gives Curie Temperatures between 500 and $700 \mathrm{~K}$, which is observed in Fig. 7. This is in line with our supposition that each transition is representative of a particular region in the microstructure.

$\mathrm{Na}$ et al.'s paper ${ }^{7}$ studied $\mathrm{CoFeNiCr}$ and $\mathrm{CoFeNiCrAl}$, and found that the CoFeNiCr alloy was paramagnetic at room temperature, with a $\mathrm{T}_{\mathrm{c}}=104 \mathrm{~K}$ and a saturation magnetisation of $0.5 \mathrm{Am}^{2} / \mathrm{kg}$. For the CoFeNiCrAl alloy, the $\mathrm{T}_{\mathrm{c}}$ was $277 \mathrm{~K}$ and the saturation magnetisation was $25 \mathrm{Am}^{2} / \mathrm{kg}$. In our work, we reduced the Ni and $\mathrm{Cr}$ percentage in the alloys and this has improved the magnetic properties as all the alloys we measured were magnetic at room temperature with a $\mathrm{T}_{\mathrm{c}}>400 \mathrm{~K}$. While the saturation magnetisation of the $\mathrm{n}-\mathrm{Al}_{0.0}$ alloy was a factor of 50 larger than $\mathrm{Na}$ 's $\mathrm{CoFeNiCr}$ alloy and the $\mathrm{n}-\mathrm{Al}_{1.0}$ saturation magnetisation was a factor 4 larger than Na's CoFeNiCrAl alloy.

Magnetic properties of the phases: $\mathbf{M}_{\mathbf{s}}$. The magnetisations presented in Fig. 6 were determined using the sample's total mass (i.e. $M=\frac{\text { moment }}{\text { total mass }}$ ). Based on Fig. 6a the increase in magnetisation for the AlCoNi $\mathrm{T}_{\mathrm{C}}$ is much larger than for the $\mathrm{FeCr}_{\mathrm{C}}$. Our earlier analysis shows that between 700 and $900 \mathrm{~K}$ the FeCr-rich phase is the only magnetic component (the AlCoNi-rich phase appears to be paramagnetic at this temperature as per the

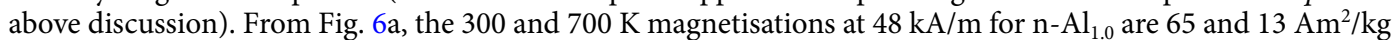
respectively; implying that the $\mathrm{AlCoNi}$-rich and $\mathrm{FeCr}$-rich phases magnetisations are 52 and $13 \mathrm{Am}^{2} / \mathrm{kg}$ respectively. At first glance this implies that the AlCoNi phase appears to be more magnetic than FeCr. However, the FeCr-rich phase contributes less than half the total mass of the sample at $700 \mathrm{~K}$, but all the measured magnetic moment, as the temperature is higher than the AlCoNi phase $\mathrm{T}_{c}$. Thus, the presented magnetisations are misleading in this temperature range. Analysis is non-trivial as both phases contribute to the magnetic behaviour at lower temperatures making it difficult to study each phase in isolation. One possible solution is to take the measured magnetic moment above the AlCoNi-rich $\mathrm{T}_{\mathrm{c}}$ where only the FeCr-rich phase contributes magnetically, and determine the $\mathrm{FeCr}$ phase saturation magnetisation by dividing by the FeCr mass. This value can then be subtracted from the total magnetisation in order to evaluate the contribution from each phase.

We therefore do the following: the magnetic moment (in $\mathrm{Am}^{2}$ ) of the FeCr-rich phase in the $\mathrm{n}-\mathrm{Al}_{0.5}, \mathrm{n}-\mathrm{Al}_{1.0}$, and $\mathrm{n}-\mathrm{Al}_{1.5}$ samples at $700 \mathrm{~K}$ and $185 \mathrm{kA} / \mathrm{m}$ were divided by the mass fraction of the phase using a rules-ofmixtures approach to determine the saturation magnetisation of the $\mathrm{FeCr}$ phase. The values were found to be 12, 72 , and $47 \mathrm{Am}^{2} / \mathrm{kg}$ respectively (cf. Fig. 6d). This suggests that the FeCr-rich nanoparticles/phase dominate the total saturation magnetisation of the $\mathrm{n}-\mathrm{Al}_{1.0}$ and $\mathrm{n}-\mathrm{Al}_{1.5}$ samples. As discussed, a rough estimate of the saturation magnetisation of the CoNiAl phase can be calculated from the total magnetisation of the sample by subtracting the $\mathrm{FeCr}$ saturation magnetisation. This gives 10,24 , and $21 \mathrm{Am}^{2} / \mathrm{kg}$ respectively for the $\mathrm{n}-\mathrm{Al}_{0.5}, \mathrm{n}-\mathrm{Al}_{1.0}$, and $\mathrm{n}-\mathrm{Al}_{1.5}$ samples. The results suggest that the matrix is weakly magnetic compared to the $\mathrm{FeCr}$ nanoparticles.

The Ni content influences the magnetisation magnitude as with lower Ni:Co and $\mathrm{Ni}: \mathrm{Al} \mathrm{ratios}{ }^{48}$ the larger the magnetisation observed; this trend corresponds with increasing $\mathrm{Al}$ addition. This is also observed in Fig. 6a, where the $\mathrm{n}-\mathrm{Al}_{0.5}$ has a lower total saturation magnetisation at $300 \mathrm{~K}$ compared to $\mathrm{n}-\mathrm{Al}_{1.0}$, and $\mathrm{n}-\mathrm{Al}_{1.5}$.

The $\mathrm{n}-\mathrm{Al}_{1.0}$ saturation magnetisation for the $\mathrm{FeCr}$ nanoparticles also correlates well with the values given for the $\mathrm{FeCr}$-rich nanoparticles ${ }^{45}$. (1) The reduction in the saturation magnetisation of the $\mathrm{n}-\mathrm{Al}_{1.5}$ sample compared to the $\mathrm{n}-\mathrm{Al}_{1.0}$ ties in with the reduction in the Curie Temperature; and (2) The large change in the FeCr $\mathrm{M}_{\mathrm{s}} \mathrm{val}$ ues observed from our results in comparison to the bulk values suggests that either the nanoparticles contain impurities (from the AlCoNi-rich phase) or the particle size strongly influences the saturation magnetisation.

Mechanism for enhanced magnetisation in $\mathrm{n}-\mathrm{Al}_{1.0}$. Assuming all $\mathrm{Co} / \mathrm{Cr} / \mathrm{Fe} / \mathrm{Ni} / \mathrm{Al}$ elements remain in solution, a modification of the Slater-Pauling curve with the Mulliken electronegativity predicts a reduction in saturation magnetic moment per atom with $>\mathrm{Al}$ despite dilution of the ferromagnetic $\mathrm{Fe} / \mathrm{Co} / \mathrm{Ni}$ components. 
From our experimental results, the saturation magnetic moment is maximum at $\mathrm{n}-\mathrm{Al}_{1.0}$; by assuming $\mathrm{FeCr}$ and AlCoNi segregation the modified Slate-Pauling curve predicts that the saturation magnetic moment will be reached at a value of $\mathrm{n}-\mathrm{Al}_{0.5}$. After considering the lack of $\mathrm{d}$-electrons in Al's valence orbitals ${ }^{49}$ which contributes to the prediction error; this suggests that phase separation enhances sample magnetisation in this system.

In a similar CoCrFeNi system, spin-driven ordering was observed in an ordered FCC phase $\left(\mathrm{L} 1_{2}\right)$, reducing the magnetisation due to antiferromagnetic $\mathrm{Cr}$ ordering ${ }^{13}$. Spin-driven ordering may also occur in the $\mathrm{n}-\mathrm{Al}_{\mathrm{x}} \mathrm{BCC}$ compositions; in the FeCr B2 system (which is the ordered BCC phase), the ferromagnetic/antiferromagnetic transition occurs from $2.88 \AA$ and below (Wigner-Seitz radius, $\left.r_{w s}: 1.418 \AA\right)^{50}$. Figure 7 a shows a comparison of the averaged Wigner-Seitz radius of the phases with sample magnetisation values, with both trends although being non-linear are in good agreement with one another. The lattice distortion between the AlCoNi-rich matrix and the $\mathrm{Fe}-\mathrm{Cr}$ precipitates is analogous to an imposed dilatational strain on the system, reducing the atomic density of the FeCr rich precipitates. The term 'strain energy' used here is a mechanical energy term with long range order in the alloy system that is separate from its chemical energies ${ }^{34}$. Furthermore, since (1) In antiferromagnetic $\mathrm{Cr}$ decreased sensitivity of the spin-density wave to compensate for strain energies occurs with lattice expansion $^{51}$, and (2) In Yang et al.'s work Cr nanoparticles may transition to ferromagnetism when atomic-scale disorder is present ${ }^{14}$, it is of interest to investigate how the strain energy changes with respect to magnetisation.

The elastic strain energy may be evaluated through the following equation ${ }^{52}$ :

$$
\Delta G_{s}=\frac{2}{3} G \Delta^{2} V_{b} E\left(\frac{y}{x}\right),
$$

where $E(y / x)$ is the elastic strain energy of the precipitate that is dependant on its shape, $G$ is the shear modulus of the matrix, and $\Delta^{2}$ is the volume misfit of the precipitate given by $\Delta=\left(v_{b}-v_{a}\right) / v_{b}$ where $v_{b}$ is the volume of the unconstrained precipitate, and $v_{a}$ is the volume of the unconstrained matrix hole. Thus, the magnetisation may be studied as a function of the nanoprecipitates observed in the microstructure. The equilibrium shape of a precipitate is the result of balancing between the elastic strain energy and interfacial energy, which may influence magnetic behaviour ${ }^{53}$. The interfacial energy may be evaluated as a function of the coherent precipitate shape, $L^{54}$ :

$$
L=\frac{\varepsilon^{2} G r}{s},
$$

where $\varepsilon$ is the lattice misfit between the particle and matrix, $r$ is the particle size, and $s$ is the interfacial energy. Via our experimental results, the mathematical relationships provide a way to use the equations as numerical laboratory to relate the relative changes in elastic strain energy and interfacial energy with magnetisation behaviour. In this analysis, the shear modulus is approximated by taking the rules-of-mixtures from first-principles calculations of the pure elements ${ }^{55}$, the lattice and volume misfit is obtained from converting the matrix XRD lattice parameters and $\mathrm{Fe}_{2} \mathrm{Cr}$ precipitate volume in Ref. ${ }^{55}$ to Wigner-Seitz radii, $E(y / x)$ and $L$ are constants dependant on the particle shape where $\mathrm{L}=1$ and $E(y / x)=1$ for spherical precipitates, $\mathrm{L}=10$ and $E(y / x)=0.75$ for lath-like precipitates, and the particle size is determined from the SEM analysis.

Calculations of $s$ and $\Delta G_{s}$ are shown in Fig. $7 \mathrm{~b}$ showing that the strain energy, $\Delta G_{s}$ is maximum for $\mathrm{n}-\mathrm{Al}_{0.5}$, whilst the interfacial energy is maximum for $\mathrm{n}-\mathrm{Al}_{1.0}$. The nucleation of a secondary phase proceeds when the elastic strain energy is sufficient to overcome the chemical potential of the new phase ${ }^{33}$, which may explain the excess elastic strain observed in $\mathrm{n}-\mathrm{Al}_{0.5}$ as the $\mathrm{BCC}$ phase is stabilised then. Changes in interfacial energy is normally expected to correspond to changes in the elastic strain energy as they balance each other out, and the increase in $\mathrm{n}-\mathrm{Al}_{1.0}$ is unexpected. Plotting $s / \Delta G_{s}$ against the magnetisation at $400 \mathrm{kA} / \mathrm{m}$ suggests that an increase in magnetisation occurs as long as the change in interfacial energy exceeds the change in elastic strain energy. As the interfacial energy in the system can be affected by magnetic behaviour, it may be that the microstructure may have Cr-depleted/enriched regions for certain compositions as the EDS line scans show possible Al-Cr separation for both $\mathrm{n}-\mathrm{Al}_{0.5}$ and $\mathrm{n}-\mathrm{Al}_{1.5}$ (cf. Supplementary Fig. A6) but is much lower for $\mathrm{n}-\mathrm{Al}_{1.0}$. Further studies on the magnetic structure will be required to understand the complex behaviour exhibited here, such as in-depth numerical analyses on the interfacial and strain energies and better magnetic characterisation.

\section{Conclusions}

The designed reduction in the $\mathrm{Ni}$ and $\mathrm{Cr}$ content here to form $\mathrm{CoFeNi} \mathrm{F}_{0.5} \mathrm{Cr}_{0.5}-\mathrm{Al}_{\mathrm{x}}$ alloys has led to a rebalancing of the AlNiCo and FeCr stoichiometries, reducing the FCC stability and therefore enhancing the BCC/B2 stability. Experimental results suggest that the competition between both phases lead to the formation of FeCr-rich and AlNiCo-rich phases. At higher $\mathrm{Al}$ additions, an $\mathrm{AlCoNi}$-rich matrix with $\mathrm{FeCr}$ spherical nanoprecipitates were observed. The size of the nanoprecipitates appear to scale with $\mathrm{Al}$ addition, although grain sizes appear to reach a minimum for $\mathrm{n}-\mathrm{Al}_{1.0}(196 \mu \mathrm{m})$ before increasing again with further $\mathrm{Al}$ addition. These results are in agreement with the inference of the importance of the AlNiCo-FeCr balancing and suggests that $\mathrm{Al}$ addition initially maximises the grain boundary energy before reaching some critical threshold.

From the magnetisation data, two Curie Temperatures were measured, which were associated with the two different phases. It was also found that the addition of $\mathrm{Al}$ increased the overall magnetisation of the sample, while maintaining the soft magnetic properties for all temperatures. It was also found that decreasing the concentration of $\mathrm{Ni}$ and $\mathrm{Cr}$ within the sample increased both the saturation magnetisation and the Curie Temperature. The fact that the $\mathrm{FeCr}$ nanoprecitates appear to continue reducing in size suggests that whilst the microstructural behaviour is may be naively described through $\mathrm{Al}$ additions, the magnetic behaviour is affected by a combination of both the inter-phase interactions and nanoprecipitate size. 
These results demonstrate the ability to design functional new complex concentrated alloys by utilising already-known concepts in the literature.

Received: 24 February 2020; Accepted: 17 July 2020

Published online: 02 September 2020

\section{References}

1. Miracle, D. B. \& Senkov, O. N. A critical review of high entropy alloys and related concepts. Acta Mater. 122, 448-511 (2017).

2. Tsai, M.-H. \& Yeh, J.-W. High-entropy alloys: A critical review. Mater. Res. Lett. 2, 107-123 (2014).

3. Leong, Z., Huang, Y., Goodall, R. \& Todd, I. Electronegativity and enthalpy of mixing biplots for High Entropy Alloy solid solution prediction. Mater. Chem. Phys. https://doi.org/10.1016/j.matchemphys.2017.09.001 (2017).

4. Poletti, M. G. \& Battezzati, L. Electronic and thermodynamic criteria for the occurrence of high entropy alloys in metallic systems. Acta Mater. 75, 297-306 (2014).

5. Andreoli, A. F. et al. The elastic-strain energy criterion of phase formation for complex concentrated alloys. Materialia 5, 100222 (2019).

6. Zuo, T. et al. Tailoring magnetic behavior of CoFeMnNiX (X = Al, Cr, Ga, and Sn) high entropy alloys by metal doping. Acta Mater. 130, 10-18 (2017).

7. Na, S.-M., Yoo, J.-H., Lambert, P. K. \& Jones, N. J. Room-temperature ferromagnetic transitions and the temperature dependence of magnetic behaviors in FeCoNiCr-based high-entropy alloys. AIP Adv. 8, 056412 (2018).

8. Kormann, F. et al. "Treasure maps" for magnetic high-entropy-alloys from theory and experiment. Appl. Phys. Lett. 107, 142404 (2015).

9. Lucas, M. S. et al. Magnetic and vibrational properties of high-entropy alloys. J. Appl. Phys. 109, 7 (2011).

10. Lucas, M. S. et al. Thermomagnetic analysis of FeCoCrxNi alloys: Magnetic entropy of high-entropy alloys. J. Appl. Phys. 113, 17A923 (2013).

11. Uporov, S., Bykov, V., Pryanichnikov, S., Shubin, A. \& Uporova, N. Effect of synthesis route on structure and properties of AlCoCrFeNi high-entropy alloy. Intermetallics 83, 1-8 (2017).

12. Wang, W.-R., Wang, W.-L. \& Yeh, J.-W. Phases, microstructure and mechanical properties of AlxCoCrFeNi high-entropy alloys at elevated temperatures. J. Alloys Compd. 589, 143-152 (2014).

13. Niu, C. et al. Spin-driven ordering of $\mathrm{Cr}$ in the equiatomic high entropy alloy NiFeCrCo. Appl. Phys. Lett. 106, 161906 (2015).

14. Yang, S. et al. Robust ferromagnetism of chromium nanoparticles formed in superfluid helium. Adv. Mater. 29, 1604277 (2017).

15. Ma, Y. et al. The BCC/B2 morphologies in AlxNiCoFeCr high-entropy alloys. Metals 7, 57 (2017).

16. Choudhuri, D. et al. Change in the primary solidification phase from fcc to bcc-based B2 in high entropy or complex concentrated alloys. Scr. Mater. 127, 186-190 (2017).

17. Linden, Y., Pinkas, M., Munitz, A. \& Meshi, L. Long-period antiphase domains and short-range order in a B2 matrix of the AlCoCrFeNi high-entropy alloy. Scr. Mater. 139, 49-52 (2017).

18. Ma, Y. et al. Controlled formation of coherent cuboidal nanoprecipitates in body-centered cubic high-entropy alloys based on $\mathrm{Al}_{2}(\mathrm{Ni} \mathrm{Co}, \mathrm{Fe}, \mathrm{Cr}) 14$ compositions. Acta Mater. 147, 213-225 (2018).

19. Xia, Z. X., Zhang, C., Lan, H., Liu, Z. Q. \& Yang, Z. G. Effect of magnetic field on interfacial energy and precipitation behavior of carbides in reduced activation steels. Mater. Lett. 65, 937-939 (2011).

20. Brunton, S. L. \& Kutz, J. N. Methods for data-driven multiscale model discovery for materials. J. Phys. Mater. 2, 044002 (2019).

21. Wang, Y. et al. Materials discovery via CALYPSO methodology. J. Phys. Condens. Matter 27, 203203 (2015).

22. Zunger, A. Inverse design in search of materials with target functionalities. Nat. Rev. Chem. 2, 0121 (2018).

23. PowDLL a reusable. NET component for interconverting powder diffraction data: recent developments " ICDD Annual Spring Meetings. Powder Diffr. 28, 137-148 (2013).

24. Wolfram Research, Inc., Mathematica, Version 12.1, Champaign, IL (2020).

25. Hume-Rothery, W., Smallman, R. E. \& Haworth, C. W. The Structure of Metals and Alloys (The Institute of Metals, London, 1988).

26. Guo, S., Ng, C., Lu, J. \& Liu, C. T. Effect of valence electron concentration on stability of fcc or bcc phase in high entropy alloys. J. Appl. Phys. 109, 10 (2011).

27. Bakker, H. \& Miedema, A. Enthalpies in Alloys: Miedema's Semi-Empirical Model (Trans Tech Publications, Zurich, 1998).

28. Cunliffe, A., Plummer, J., Figueroa, I. \& Todd, I. Glass formation in a high entropy alloy system by design. Intermetallics 23, 204-207 (2012).

29. Yang, X. \& Zhang, Y. Prediction of high-entropy stabilized solid-solution in multi-component alloys. Mater. Chem. Phys. 132, 233-238 (2012).

30. Tsai, M.-H. et al. Criterion for sigma phase formation in Cr- and V-containing high-entropy alloys. Mater. Res. Lett. 1, 207-212 (2013).

31. A new semi-empirical method based on a distorted tetragonal scheme for the structure prediction and alloy design of multiplecomponent alloys. (University of Sheffield, Sheffield, 2017).

32. Lavrentiev, M. Y. et al. Magnetic cluster expansion simulation and experimental study of high temperature magnetic properties of Fe-Cr alloys. J. Phys. Condens. Matter 24, 326001 (2012).

33. Kashchiev, D. Nucleation Basic Theory with Applications (Butterworth Heinemann, Oxford, 2000).

34. Christian, J. W. The theory of transformations in metals and alloys. Pt. 2: [...]. (Pergamon, 2002).

35. Nie, J.-F. Physical metallurgy of light alloys. In Physical Metallurgy 2009-2156 (Elsevier, Amsterdam, 2014). https://doi.org/10.1016/ B978-0-444-53770-6.00020-4.

36. Fratzl, P., Penrose, O. \& Lebowitz, J. L. Modeling of phase separation in alloys with coherent elastic misfit. J. Stat. Phys. 95(1429), 1503 (1999).

37. Voorhees, P. W., McFadden, G. B. \& Johnson, W. C. On the morphological development of second-phase particles in elasticallystressed solids. Acta Metall. Mater. 40, 2979-2992 (1992).

38. Dregia, S. A. \& Wynblatt, P. Equilibrium segregation and interfacial energy in multicomponent systems. Acta Metall. Mater. 39, 771-778 (1991).

39. Inman, M. C. \& Tipler, H. R. Interfacial energy and composition in metals and alloys. Metall. Rev. 8, 105-166 (1963).

40. Soulairol, R., Fu, C.-C. \& Barreteau, C. Magnetic and energetic properties of low-index Cr surfaces and Fe/Cr interfaces: A firstprinciples study. Phys. Rev. B 84, 155402 (2011).

41. Wang, Y. et al. A thermodynamic description of the Al-Co-Ni system and site occupancy in Co + AlNi3 composite binder phase. J. Alloys Compd. 687, 855-866 (2016).

42. Liu, L. et al. Pressure-induced magnetovolume effect in CoCrFeAl high-entropy alloy. Commun. Phys. 2, 42 (2019).

43. Chou, H. P., Chang, Y. S., Chen, S. K. \& Yeh, J. W. Microstructure, thermophysical and electrical properties in Al x CoCrFeNi (0 $\leq \mathrm{x} \leq 2)$ high-entropy alloys. Mater. Sci. Eng. B 163, 184-189 (2009).

44. Ropo, M. et al. Theoretical evidence of the compositional threshold behavior of FeCr surfaces. Phys. Rev. B 76, 220401 (2007). 
45. Shafranovsky, E. A. et al. Structural and magnetic properties of bulk alloys and aerosol nanoparticles in the Fe100-xCrx system. J. Alloys Compd. 416, 51-57 (2006).

46. Saito, T. Magnetic properties of Co-Al-Ni melt-spun ribbon. J. Appl. Phys. 100, 053916 (2006).

47. Ishida, K. Recent progress on Co-base alloys-phase diagrams and application. Arch. Metall. Mater. 53(4), 1075-1088 (2008).

48. Huang, S. et al. Mechanism of magnetic transition in FeCrCoNi-based high entropy alloys. Mater. Des. 103, 71-74 (2016).

49. Leong, Z., Todd, I. \& Goodall, R. Structural dependency of some multiple principal component alloys with the Thomas-FermiDirac electron density. Scr. Mater. 146, 95-99 (2018).

50. Soulairol, R., Barreteau, C. \& Fu, C.-C. Interplay between magnetism and energetics in Fe-Cr alloys from a predictive noncollinear magnetic tight-binding model. Phys. Rev. B 94, 024427 (2016).

51. Marcus, P. M., Qiu, S.-L. \& Moruzzi, V. L. The mechanism of antiferromagnetism in chromium. J. Phys. Condens. Matter 10, 6541-6552 (1998).

52. Nabarro, F. R. N. The strains produced by precipitation in alloys. Proc. R. Soc. Math. Phys. Eng. Sci. 175, 519-538 (1940).

53. Calvo-Dahlborg, M. et al. Interplay of electronic, structural and magnetic properties as the driving feature of high-entropy CoCrFeNiPd alloys. J. Phys. Appl. Phys. 50, 185002 (2017).

54. Wang, Q. et al. Coherent precipitation and strengthening in compositionally complex alloys: A review. Entropy 20, 878 (2018).

55. Shang, S. L. et al. First-principles calculations of pure elements: Equations of state and elastic stiffness constants. Comput. Mater. Sci. 48, 813-826 (2010).

\section{Acknowledgements}

ZYL would like to thank Dr. E. Hernandez for his help with the etching process, Prof. I. Todd for his help and advice for the microstructural characterisation, and Ms. M. Rodriguez for aiding in the Bakelite characterisation. The authors would also like to thank Dr. J. Thompson for his help and advice with the MPMS-3 SQUID-VSM, and Dr. R. Robinson and Dr. A. Welbourne for useful discussions on the text. This work was supported by the Royal Society Mid-Career Leverhulme Trust Fellowship scheme (SRF $\backslash R 1 \backslash 180020)$ and the Leverhulme Trust (RPG-2018-324).

\section{Author contributions}

N.A.M.: Experimental (35\%), analysis (35\%), writing (40\%), experimental design (50\%), editing (33\%). L.C.R.: experimental (25\%), analysis (10\%), Writing (10\%). XJW: experimental (20\%). A.Q.N.: experimental (15\%), writing (10\%), analysis (15\%), experimental design (10\%), editing (33\%). Z.Y.L.: experimental (15\%), analysis (40\%), writing (40\%), experimental design (40\%), alloy design (100\%), editing (33\%).

\section{Competing interests}

The authors declare no competing interests.

\section{Additional information}

Supplementary information is available for this paper at https://doi.org/10.1038/s41598-020-71463-3.

Correspondence and requests for materials should be addressed to Z.L.

Reprints and permissions information is available at www.nature.com/reprints.

Publisher's note Springer Nature remains neutral with regard to jurisdictional claims in published maps and institutional affiliations.

Open Access This article is licensed under a Creative Commons Attribution 4.0 International License, which permits use, sharing, adaptation, distribution and reproduction in any medium or format, as long as you give appropriate credit to the original author(s) and the source, provide a link to the Creative Commons licence, and indicate if changes were made. The images or other third party material in this article are included in the article's Creative Commons licence, unless indicated otherwise in a credit line to the material. If material is not included in the article's Creative Commons licence and your intended use is not permitted by statutory regulation or exceeds the permitted use, you will need to obtain permission directly from the copyright holder. To view a copy of this licence, visit http://creativecommons.org/licenses/by/4.0/.

(c) The Author(s) 2020 